DOI: https://doi.org/10.24164/prosiding.v3i1.27

\title{
SIKAP SPIRITUAL MASYARAKAT JAWA TERHADAP FENOMENA MISTIK \\ KAJIAN TERHADAP SIKAP ORGANISASI NAHDHATUL ULAMA DAN MUHAMMADIYAH TERHADAP FENOMENA MISTIK
}

\author{
Javanese Spiritual Attitude towards Mystical Phenomenon Review \\ of The Organization of Nahdhatul Ulama and Muhammadiyah \\ in the Mystical Phenomenon
}

Arif Budiman

Madrasah Aliyah Negeri (MAN) 21 Jakarta

Jalan Tambun Rengas No. 48 RT 001 RW 07 Rorotan, Cilincing Jakarta Utara 14140

E-mail: arifbudiman@man21-jkt.sch.id

\begin{abstract}
Lately, the mystical phenomenon is being discussed in public spaces. Especially, after several private TV stations have made programs with mystical themes. As a matter offact, these mystical things have a correlation with spirituality (Islam). Mystical phenomena that exist on TV such as "Karma" and "Sirqol" or Siraman Qolbu, have recently become phenomenal. This fact seems to emphasize that Islam cannot stop at things that are ritualistic or only physical, but there are other aspects. One of them is the mystical aspect only. How is this mystique (read: occult) responded to by Islamic groups? Especially how NU and Muhammadiyah have responded to this phenomenon. NU tends to be acculturated, while Muhammadiyah refuses. Muhammadiyah's rejection does not necessarily eliminate the mystical tradition. Instead of disappearing mystical culture, the reality is now growing. The conclusion can be drawn that Religion (read: Islam) must not only be rational, but also that Religion (read: Islam) has arguments or answers to mystical problems. This research method is the historical method which includes. Heuristics in the form of collecting existing facts, verification is carried out by conducting source criticism, interpretation, namely interpreting and analyzing these facts. And the final stage of this research is historiography, which is to write down the results of the interpretation of the previous stages.
\end{abstract}

Keywords: Mystical, Mystical, Experience, Spirituality and Javanese Society.

\section{AbSTRAK}

Akhir-akhir ini fenomena mistik ramai diperbincangkan di ruang publik. Apalagi setelah beberapastasiun TV swasta membuat program dengan tema mistik.Sebagai sebuah kenyataan, hal-hal mistik ini memiliki korelasi dengan spiritualitas (Islam).Fenomena mistikyang ada di TV semisal "Karma" dan "Sirqol" atau Siraman Qolbu, akhir-akhir ini menjadi sangat fenomenal. Fakta ini seperti sedang menegaskan bahwa Islam tidak bisa berhenti pada hal yang bersifatritualistik atau hanya fisik, namun ada aspek lain. Salah satunya adalah aspek mistik saja. Bagaimanakah mistik (baca: klenik) ini disikapi oleh kelompok-kelompok Islam? Khususnya bagaimana NU dan Muhammadiyah mensikapi fenomena ini. NU cenderung berakulturasi, sementara Muhammadiyah menolak. Penolakan Muhammadiyah tidak serta merta menghilangkan tradisi mistik. Alih-alih budaya mistik itu hilang, realitasnya, kini makin berkembang. Kesimpulan dapat ditarik bahwa Agama (baca: Islam) bukan hanya harus 
rasional, namun juga Agama (baca: Islam) punya argumentasi atau jawaban atas masalah mistis. Metode penelitian ini adalah Metode Sejarah yang meliputi. Heuristik berupapengumpulan fakta-fakta yang ada, verifikasi dilakukan dengan melakukan kritik sumber, interpretasi yaitu menafsirkan dan melakukan analisis terhadap fakta-fakta tersebut. Dan tahap akhir penelitian ini adalah historiografi yaitu menuliskan hasil interpretasi dari tahap-tahap yang dilakukan sebelumnya.

Kata kunci: Mistik, Pengalaman Mistik, Spiritualitas dan Masyarakat Jawa.

\section{PENDAHULUAN}

$\mathrm{A}$ khir-akhir ini, marak cerita mistik berkembang di masyarakat kita terutama disebabkan oleh pengaruh dua acara berbau mistik di TV swasta Nasional kita. Yang pertama "Karma" yang ditokohi Roy Kiyoshi dan "Siraman Qolbu" yang ditokohi ustad Dhanu. Jemaah pengajian dengan segmen ini ataupun masyarakat seperti menemukan Oase di tengah sahara spiritual yang kering. Cerita-cerita mistik dalam acara tersebut menghadirkan kerinduan yang lama yaitu cerita yang lama hilang (atau dihilangkan) dari masyarakat Jawa namun tumbuh subur di Masyarakat dalam arti tidak pernah diangkat ke permukaan. Cerita-cerita kesurupan, pesugihan, hingga kehadiran sosok Sabdo Palon hingga Mbah Semar maupun Nyi Roro Kidul menjelaskan horizon masyarakat Jawa menjadi satu kesatuan yang tidak terpisahkan.

Adapun fenomena mistik itu sangat ternarasikan dalam bentuk benda-benda maupun kisah-kisah mistik. Kisah ini seperti pemaparan Mas Dikontole yang menceritakan bahwa dirinya adalah Inkarnasi dari Aryawiraraja. Tentang diri Mas Dikontole yang oleh seorang wanita dalam kisah itu dinyatakan sebagai Titisan Aryawiraraja (Kompasiana.com, 2012:1). Hal ini disampaikan seorang wanita yang menemuinya dan menyatakan Mas Dikontole sebagai Titisan Aryawiraraja. Sebagai tambahan, disini saya mau menceritakan Kisah Penulis sendiri yang menemukan
Fenomena Gaib (Ghaib) saat tertidur dalam masjid Al Huda Bonjok yang bertemu dengan sosok gaib. Cerita penulis sendiri ini bisa jadi menjadi bahan tulisan ini walau subjektivitas yang akan sulit diterima. Tetapi saya ingin mengatakan saya mengalami itu. Terhadap kisah ini, Penulis sendiri ingin mengatakan kisah yang saya alami ini sebagai sebagai pengalaman spiritual.

\section{METODOLOGI PENELITIAN}

Penelitian Mistik dalam penelitian ini adalah upaya mengungkap fakta-fakta mistik yang terekam atau diceritakan dalam bentuk atau tulisan yaitu fakta obyektifyang bisa dipertanggungjawabkan atau bisa dibuktikan kebenarannya, meskipun hal tersebut tak menjelaskan fakta yang sebenarnya, tapi faktanya hal ini ternarasikan dalam dalam bentuk mitos ataupun cerita sejenis semisal dalam bentuk benda-benda yang dianggap mengandung kekuatan mistik.Kesulitan penelitian mistik adalah ketika harus berbicara tentang hal mistiknya itu sendiri, jelas itu, tentu menjadi sebuah kemustahilan karena hal ini menyangkut metodologis

Persoalan ini munculterkait tahap-tahap dalam penelitian, mengingat objek penelitian ini bukan objek yang masuk dalam ranah metafisis. Meski demikian upaya untuk menggali dan menyebutkankecendrungankecenderungantentang ini adalah riil adanya. Penelitian mistik akan menemui kendala utama terkait dengan objektivitas sumber. Contoh pembicaraan dalam Serat Sabdo 
Palon yang memuat dialog Semar dengan Syeh Subakir. Tentu ada interpretasi subjektif. Benarkah terjadi pembicaraan antara Semar dan Syeh Subakir itu.? Dalam konteks historis, ruang dan waktu jelas tak bisa dipertanggung jawabkan. Tapi sebagai kisah yang hidup di masyarakatm itu adalah nyata sebab sumbernya adalah serat, sementara itu Semar sendiri digambarkan sebagai mahluk halus yang kasat mata. Bahkan ada sumber yang mengatakan bahwaa ia adalah iblis yang berwujud manusia. Semar dalam serat Sabdo Palon itu menerima kekalahan dari Syeh Subakir, namun ia wanti-wanti akan kembali bangkit jika situasi yang diprediksikannya terjadi semisal adanya Pemimpin yang tak amanah, tidak mencintai rakyat serta tak mengayomi semua agama. Bahkan Semar memberikan tanda-tanda akan kehadiranya kembali ke muka bumi. Dalam Serat itu diceritakan Semar akan datang lagi dan akan mengganti ajaran yang dibawa Syeh Subakir ini dengan Agama Budi. Dalam serat Darmogandul (Swei, 1958) agama budi yang disebutkan dalam serat itu adalah agama kaweruh. Menurut Susiyanto, peneliti Pusat Studi Peradaban Islam, yang dimaksud dengan agama kawruh dalam Serat Darmagandul tersebut, tidak lain adalah Kristen.

Kaidah ilmiah selalu menuntut identifikasi seperti empiris, objektif, sistematis. Sementara Mistik sulit dimasukan dalam dalam kategori itu. Namun ketika hal mistik itu telah terkatakan, terdokumentasikan dan ternarasikan, maka menurut saya ia sebagai ada dan nyata meski dalam kata atau cerita bisa diteliti. Terdokumentasikan itu maksudnya ada fakta dan dokumennya. Maka itu bisa dihadirkan ataupun diteliti yaitu dokumentasi. Sesudahnya, mistik adalah bukan suatu kesulitan atau kemustahilan untuk tetap bisa diteliti.

Penelitian Karen Armstrong tentang sejarah tuhan, bisa menjadi contoh bagaimana metode penelitian ini bekerja untuk "dzat" dalam arti sama-sama meneliti objek mistik (Amstrong, 2004: 21). Karen Armstrong

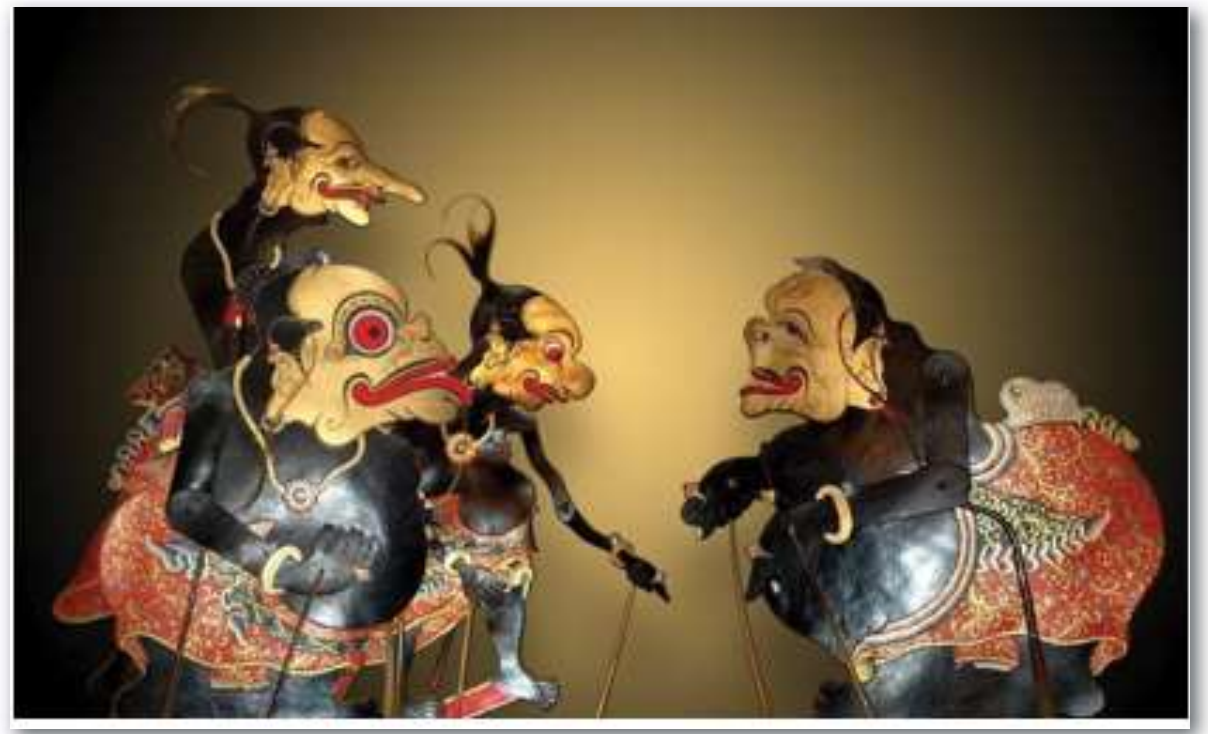

Gambar 1. Sosok Semar dan Punakawan (Sumber: Hadi Suprapto, https://www.hops.id, 2020: 1) 
katakan bahwabuku History Of God (penelitian dia) bukan tentang sejarah realitas Tuhan yang takterucapkan itu, yang berada di luar waktu dan perubahan, tetapimerupakan sejarah persepsi umat manusia tentang Tuhan sejak era nabi Ibrahim hingga hari ini. Bagi penulis objek penelitiannyasama yaitu hal hal yangsupranatural. Isi buku Sejarah Tuhan itu bukan berarti menjelaskan tentang bagaimana adanya Tuhan yang pertama, tapi di buku itu dipaparkan tentang jejakmanusia tentang Tuhan dalam pandangan atau buktibukti arkeologis tentang manusia bertuhan dari zaman ke zaman.

Fokus penelitian tertuju pada halhal mistik Mistik itu sendiri dalam dinamika Spiritualitas Masyarakat Jawa. Bagaimanakah Mistik ini disikapi oleh spiritualitas masyarakat Jawa? Adapun, spiritualitasnya difokuskan pada dua komunitas Spiritualitas yaitu NU dan Muhammadiyah. Inilah fokus penelitian yang ingin diajukan dalam tulisan ini. Sebesar apa pengaruh cerita itu terhadap masyarakat Jawa serta bagaimana agama (baca: NU dan Muhammadiyah) menjawab persoalan ini. Sejumlah fakta dan realitas ini dapat dibaca dalam fakta-fakta mistis

\section{PEMBAHASAN}

\section{Spiritualitas Masyarakat Jawa Kuno}

Spiritual suatu masyarakat terindikasi dalam sikap dan suasana kebatinannya terhadap lingkungan dan adanya kesadaran yang tinggi pada kekuatan adikodrati, yaitu sesuatu yang ada di luar kemampuan Manusia Jawa. Dalam beberapa terminology Agama kesadaran tertinggi itu tertuju pada Istilah Dewa dalam Hindu dan Allah dalam Islam, sebelum kedatangan semua Agama itu ke Indonesia, Nusantara sudah mengenal beberapa istilah dalam berkeyakinan. Cuma konsep berkeyakinan itu sudah ada sejak Jawa Kuno. Sebelum masuknya Hindu dan Islam keyakinan pada yang adikodrati, termanifestasi dalam acara-acara selametan

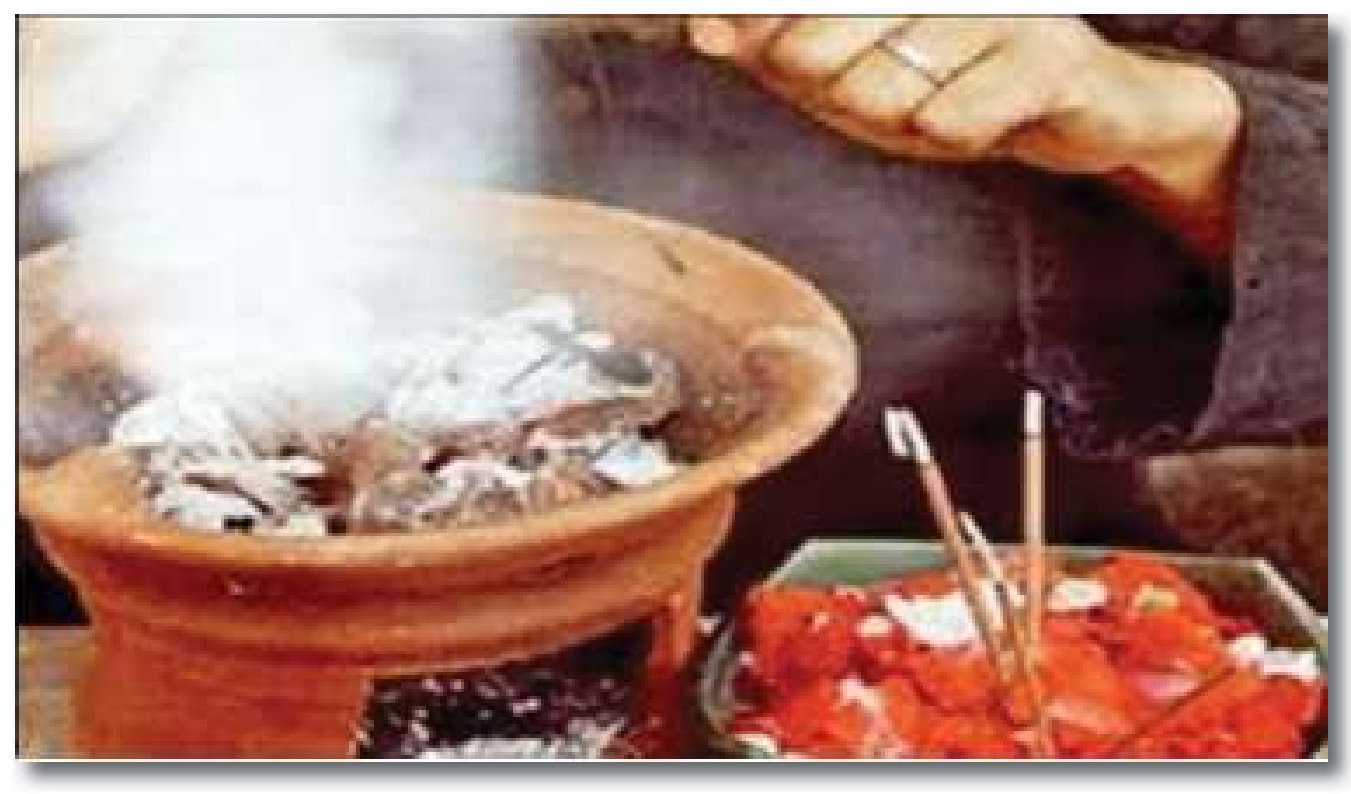

Gambar 2. Ilustrasi Kegiatan Jasa Pesugihan (Sumber: Mona Kriesdinar, https://jogja.tribunnews.com, 2019: 1) 
yang beragam karena percaya dengan mahluk-mahluk halus (Geertz, 2013: 8)

Kitab Babad Tanah Jawa menceritakan spiritualitas mulai pra-Islam hingga Mataram Islam, dan terdokumentasikan dengan baik dalam Babad Tanah Jawa dan Serat Cibolek (Woodward, 2004: 227). Kitab ini juga mengulas nilai-nilai sauatu agama tertentu dan persentuhannya dengan nilainilai kejawen, bahkan sebelum sebelum hindu Buda. Laku spiritual ini dapat dilihat, misalnya dalam laku tapa (bersemedi) sering dilakukan orang-orang pada masa jawa kuno. Pada masa ini pula sudah mulai mengenal nilai spiritualitas itu sebagai nilai keluhuran yang diajarkan oleh sosok Semar sebagai penutur nilai-nilai spiritual Jawa dalam banyak versi. Versi pertama dari serat Sabdo Palon menceritakan Ajaran Semar akan kembali hadir setelah 500 tahun, agama Semar itu dinamakan Agama Budi (Shasangka, 2017: 427). Sementara itu ada versi kedua Serat Darmogandul. Kitab ini justru menggambarkan Semar sebagai dahnyang tanah Jawa. Dan darinya mengalir doktrin spiritual Jawa Kuno. Sayangnya kitab ini sangat nyinyir sekali menilai ajaran Islam dan Serat ini dinilai mengandung bahasa tidak baik (kurang seronok yang menyudutkan Islam). Versi iniini menyebut ajaran semar ini dengan agama Kaweruh (Agama Kristen).

Beberapa versi menyebut Semar (disebut juga Semar Badranaya) sebagai sosok Iblis yang menjelma dalam sosok Manusia. Tapi jika Ia Iblis mengapa darinya lahir konsep-konsep atau Pitutur Jawa yang menurut penulis sebagai Nilai Spiritual Jawa mendalam, artinya nilai-nilai yang penuh maknaSebut saja empat ajaran Semar yang bisa dikategorikan sebagai Pitutur Spiritual yang menjiwai masyarakat Jawa pada umumnya. Bukan hanya empat ini saja tapi beberapa kitab kuno yang lain yang menyisakkan persaksian kultural tentang yang terkait dengan ajaran Semar.

Sejak lama prilaku mistik ini ada di Masyarakat Jawa hingga saat ini. Ambil contoh atau beberapa sampel yang menjadi trend masyarakat Jawa pada umumnya. Minta Pesugihan, bukan hal yang aneh. Perilaku ini telah berlangsung sangat lama. Bahkan bias dikatakan sepanjang sejarah Jawa. Hal ini banyak dilakukan oleh beberapa orang yang telah menempuhi hidup namun belum juga mendapati kemuliaan (kekayaan), karenanya ia meminta bantuan kepada para Dukun. Mulai dari tiraqatan di gua-gua hingga melakukan perjanjian mistik dengan mahluk gaib.

Tambah Pesona Diri dapat dilakukan melalui mekanisme mistik atau praktek Jasa Pesugihan, lihat ilustrasi (Gambar 2) seperti pasang susuk pasang susuk mau dengan kepemilikan besi Semar Kuning. Perilaku atau praktek inibanyak dilakukan oleh orasiapapun termasuk di dalamnya para artis yang ingin menjaga pesonanya agar selalu terlihat mempesona atau laku menjadi artis. Agar terlihat dengan penampilan wet muda dan sejenisnya. Perilaku ini dilakukan dengan melakukan pasang susuk di beberapa bagian tubuhnya, bisa di wajah, di pinggang, kaki atau bagian tubuhnya yang lain.

Perilaku Mistik ini tentu tidak semua dilakukan orang Jawa. Sebab pengaruh pemikiran Muhammadiyah dan gerakan purifikasi yang sejenisnya yang menolak Bidah seperti gerakan Salafi nyaris menolak 100 persen mistik Jawa ini. Meskipun melakukan penolakan dan upaya untuk menggerus budaya mistik ini, namun tidak sepenuhnya hilang. Kelahiran Muhammadiyah tentu banyak menggeser 
mistik ini, namun masih banyak masyarakat atau orang Jawa yang melakukan.

\section{- Sikap Spiritual}

Analisis sikap spiritualitas sebagai terminology dimaksudkan dalam penelitian untuk melihat spiritualitas adalah hal-hal yang adikodrati, yang ilahi yang melupakan sesuatu yang tak cukup dengan kata-kata manusia. Pengalaman saya sendiri ingin saya utarakan sebagai perbandingan. Saya sadar pengakuan dan pengalaman saya tidak bias menjadi bukti objektif sebab pengalaman mistikyang bercirikan subjektif, bersifat personal atau sangat pribadi. Nah, arti pengalaman ini menguatkan keyakinan bahwa Mistik adalah dimensi yang nyata. Ia ada.

Saya memasukan pengalaman spiritual dalam perspektif ini sebagai cerita mistik putih sebab pengalaman ini membahas tema Ketuhanan. Sebuah refleksi terhadap masih adanya orang yang memilih "Atheis" dalam makna yang sebenarnya. Ketika saya mengalami suasana mistikini saya bertemu dengan sosok yang tak saya kenal. Ia bisa ada alias hadir di hadapan saya, bukan ledekkan (candaan teman). Ini riil alias nyata. Sosok itu berdiri di depan saya. Buat saya ini adalah suatu pengalaman yang membuat saya semakin yakin untuk memeiliki keyakinan spiritual dan tidak atheis tentunya.

Bukan pula sikap spiritual berlebihan yang pernah menhadirkan konflik saat Syeh Siti Jenar mengajarkan Annal Haq (yang diartikan Tuhan Adalah Saya). Komunitas masyarakat Jawa saat itu tentu tidak siap atau belum siap untuk menerima ajaran Syeh SIti Jenar (Ricklefts., 2000: 83).

\section{- Analisis Mistik dan Islam}

Perilaku mistik zaman kuno tentu berbeda dengan mistik zaman sekarang. Mistik kuno sangat kuat sebab belum adanya argumentasi ataupun penjelasan ilmiah termasuk teknologi yang bisa menyanggahnya. Sebut saja konsep mistik di zaman Hindu Buda, tentu akan berbeda dalam kenyataannya dengan mistik maa Islam. Adanya perkembangan ilmu pengetahuan dan teknologi, beriring pemahaman Agama yang makin terbuka dan logis sehingga agamapun tertantang untuk logis dalam arti harus bisa dibuktikan secara logis.

Maka dalam agama ada fase purifikasi Islam di Indonesia yang pertama kali melakukan purifikasi keagamaan adalah organisasi Muhammadiyah dengan membawa tema-tema anti Takhayul, Bi'dah, Churafat. Doktrin Islam yang konservatif pun terkoreksi dan terus menyesuaikan dengan konsep-konsep modern. Sebut saja perdebatan antara arah kiblat di masjidmasjid di Yogyakarta masa Kyai Haji Ahmad Dahlan mengoreksi konservativisme pandangan agama. Dan yang umum terlihat dalam koreksi dalam masalahmasalah seperti tahhlilan, slametan dan lain sebagainya. ${ }^{1}$ (Entra, 2004: 3).

Masa Islam, mistik menemukan penyikapan berbeda abad ke-15. Islam disampaikan dengan proses yang tidak mudah. Pertentangan antara tradisi Jawa dan Islam mewarnai perjalanan spiritualitas masyarakatnya. Kedatangan Islam dua organisasi besar ini membawa pengaruh yang kuat terhadap pergeseran Hindu Budha di Jawa. (Toer, 1995: 409) cukup

\footnotetext{
1 https:/www.kompasiana.com/nugrahaentra/ 55282af5f17e6197218b45d5/sikap-muhammadiyah-tentang-tahlilan
} 
banyak menjelaskan bagaiman pergeseran Hindu oleh karena kedatangan Islam ini. Muhammadiyah misalnya membawa misi purifikasi dan menolak konsep mistik ini dalam spiritualitasnya.

\section{Sikap Dua Organisasi Islam Terbesar di Indonesia}

Penyikapan terhadap fenomena mistik itu beragam. Ada penyikapan keras menolak, namun ada juga yang menghargai tradisi. Yang menolak misalnya menilai perbuatan ini dengan sebutan bidah, melanggar Syariah dan lain sebagainya. karenanya, lewat tulisan ini, sampailah pada satu pesan penting bahwa spiritualitas semestinya memiliki wilayah dan tujuan yang sama. Jika spiritualitas membicarkan hal yang baik, di bagian mana ajaran Kejawen yang tidak baik? mulai dari slametan, Tahlilan, Ingkung hingga Penentuan Hari baik. Bukankah semua itu baik. Sebut saja organisasi Muhammadiyah, sejak awal organisasi ini dibentuk telah menolak konsep mistik dan praktek mistik dengan bentuk-bentuk penampilannya sebagai Takhayul, Bid'ah dan Churafat (TBC) (A'an Ardianto, http://www.umm.ac.id/id, hal.1). Bahkan memang kehadiranya merupakan antithesis Islam konservatif yang dinilai animistik atau warisan leluhur. Majelis Tarjih Miuhammadiyah mengeluarkan sikap bahwa warga Muhammadiyah agar mengambil sikap menjauhi atau meninggalkan perbuatan yang tidak pernah dituntunkan oleh rasulullah SAW (Fatwa Majelis Tarjih, http://m.muhammadiyah.or.id, hal. 1). Hal senada juga ditulis oleh Nugraha Entra dalam artkelnya berjudul "Sikap Muhammadiyab Tentang Tahlilan", ia menulis yang dilarang menurut Muhammadiyah adalah upacaranya yang dikaitkan dengan tujuh hari kematian, atau empat puluh hari atau seratus hari dan sebagainya (Entra, 2013:1)

Lebih lanjut, dalam tulisan Nugraha Entra dalam kolom Kompasiana mengatakan selamatan nujuh hari, empat puluh hari dan seterusnya itu adalah sisasisa pengaruh budaya animisme, dinamisme, serta peninggalan ajaran Hindu yang sudah begitu berakar dalam masyarakat kita. Karena hal itu ada hubungan dengan ibadah, maka kita harus kembali kepada tuntunan Islam. Apalagi katanya menambahkan, upacara semacam itu harus mengeluarkan biaya besar, yang kadang-kadang harus pinjam kepada tetangga atau saudaranya, sehingga terkesan tabzir (berbuat mubazir). Seharusnya, ketika ada orang yang meninggal dunia, kita harus bertakziyah/ melayat dan mendatangi keluarga yang terkena musibah kematian sambil membawa bantuan/makanan seperlunya sebagai wujud bela sungkawa. Pada waktu Ja'far bin Abi Thalib syahid dalam medan perang, Nabi saw menyuruh kepada para shahabat untuk menyiapkan makanan bagi keluarga Ja'far dan bukan malah datang ke rumah keluarga Ja'far untuk makan dan minum (Abu Daud, 1983).

Abdul Munir Mulkhan justru menggambarkan bagaimana posisi Muhammadiyah yang terikat dengan Tarjih ini menjadikan Muhammadiyah sebagai gerakan keagamaan yang anti kebudayaan dan anti keberagaman Abdul Munir Mulkhan (2012: 63). Dalam bukunya berjudu "Islam Kultural Kyai Dahlan”, Muhammadiyah dalam ikatan Tarjih itu seperti terperangkap dalam intitusionalisasi atau pelembagaan keagamaan.

Doktri Nahdlatul Ulama dibangun diatas Khithoh perjuangan organisasi yaitu organisasi yang sangat akomodatif yaitu 
sangat akulturatif dengan kebudayaan lokal. Lewat organisasi NU dengan tokohnya $\mathrm{KH}$. Hasyim Asy'ari, NU, juga sangat akomodatif terhadap berbagai mahzab (Rohinah, 2010: 84). Secara tradisi, NU sangat menghargai tradisi itu, dengan catatan tidak bertentangan dengan hokum Islam atau Syariat.

Sikap akomodatif ini jelas tergambar dalam pandangan NU pada tradisi lokal sebagaimana sikap yang dikeluarkan oleh PWNU Jawa Timur tentang tahlilan. Dalam hal ini PWNU Jatim menyatakan sikapnya atau pendiriannya sebagai organisasi keagamaan yang mengusung konsep Islam Nusantara, dimana di dalam Islam Nusantara sangat menghormati, dengan memelihara, menjaga dan melestarikan tradisi-tradisi nujuh hari, empat puluh ini (Keputusan Bahtsul Masail Maudhu'iyah, 2016 https:// ltnnujabar.or.id )

Warga NU banyak yang mempraktekkan tradisi Mistik (klenik), namun dilakukan dalam "ranah dakwah" yang masih ada di Masyarakat kita. Binhad Nurrahmat dalam bukunya Jimat NU, menyajikan fakta bagaimana NU masih kuat dengan tradisi Jimat semisal pembicaraan seputar jimat yang bertuah, dikatakan oleh Ade, salah satu penulis dibuku itu, karena huruf itu terhubung dengan alam semesta (Nurrahmat, 2014: 25). Seandainya ada warga masyarakat yang mengalami masalah Klenik, maka Ulama dan warga NU, banyak mengambil peranan disana. Ulama atau warga Muhammadiyah sebaliknya tak terlihat perannya dalam masalah ini.

\section{SIMPULAN}

Esensi utama adalah untuk menyuguhkan fakta bahwa Islam itu bukan sekedar doktrin, Islam dalam hal ini juga juga ranah mistik. Simplifikasi akibat modernisasi telah menarik spiritualitas hanya doktrin. Akibatnya Islam sebagai nilai mengalami kekeringan, dan gagal menampilkan dirinya sebagai pendamai. Dalam perkembangan ketika agama kering maka masyarakat mencari jawaban sendiri lewat leawat para pelaku mistik. Umat Islam akhirnya memilih "Tausiah Mistik" oleh para Kyai yang punya pengalaman mistik. NU, dalam hal ini menempati posisi terbaiknya yang terbukti berdamai dengan mistik.

Para wali sangat cerdas membaca celah spiritualitas Jawa tradisional yang mampu menyatu dengan nilai Islam. Karenanya dalam hal ini ada titik temu. Dan yang selanjutnya terjadi dengan praktek agama yang saya ingin sebut "anti social" karena masalah mistik buat saya adalah persoalan sosial, dan kelompok ini anti dengan mistik, artinya tak mampu dan tak mau menjawab persoalan mistik. Buat saya wajar jika masyarakat akan mencari jalannya sendiri, sebagai contoh mereka akan mencari tokoh (Agama) yang spiritual.

Peneliti merekomendasikan agar temuan ini bisa dijadikan referensi komunitas keagamaan Islam bisa Mistisisme (baca: klenik) sebagai realitas budaya. Tasawuf bisa menjadi jalan masuk yang tepat bersinggungan dengan tradisi Mistik di jawa. NU sangat kaya dengan tradisi Suluk atau tasawuf. Dunia klenik, hanyalah bagian kecil, yang teratasi oleh Tasawuf (Schimmel, 2012: 201).

\section{DAFTAR PUSTAKA}

Abu Daud, Muhamamad. 1983. Kitab Sunan Abu Daud No. 3132. Diponegoro. Bandung

Armstrong, Karen. 2004. Sejarah Tuhan: Kisah Pencarian Tuhan yang dilakukan oleh Orang-orang Yahudi 
dan Islam selama lebih dari 4.000 Tahun. Bandung: Mizan.

Geertz, Clifford. 2013. Agama Jawa: Abangan, Santri, Priayi dalam Kebudayaan Jawa. Jakarta: Komunitas Bambu.

Swie, Tan Koen. 1958. Serat Darmogandul Cetakan ke-V. Kediri

Munir Mulkhan, Abdul. 2012, Islam Kultural Kiai Dahlan: Mengembangkan Dakwah Muhammadiyah Secara Cerdas dan Maju Bersama Kiai Ahmad Dahlan. Jakarta: Grafindo Khasanah Ilmu.

Nurrohmat, Binhad dkk. 2014. Jimat NU. Arruz-Media.

Noor, Rohinah M. 2010. KH. Hasyim Asy'ari Memodernisasi NU dan Pendidikan Islam. Grafindo Khasanah Ilmu.

Ricklefts. 2000. Sejarah Modern. Yogyakarta: Gajah Mada University Press.

Schimmel, Annemarie. 2012. Dimensi Mistik Dalam Islam. Jakarta: Pustaka Firdaus.

Shasangka, Damar. 2017. Sabda Palon: Kisah Nusantara yang Disembunyikan. Dolphin. Bamten

Woodward, Mark R. 2004. Islam Kejawen: Kesalehan Normatif Versus Kebatinan. Yogyakarta. LKiS.2004

Website:

Arif Budi Utomo, Sang Penjaga (Ghaib): Kisah Spiritual Mas Dikontole. 25 Juli 2012. https://www.kompasiana. com/arifbudiutomo/5512748ba333 116359ba7e38/sang-penjaga-ghaibkisah-spiritual-mas-dikontol

Mona Kriesdinar, Jasa Pesuguhan Marak diInternet, Mulai Dari Nihai Jin, Pasang Susuk, Hingga Banjir Uang Tanpa Tumbal,15 November 2019 https://jogja.tribunnews. com/2019/11/15/jasa-pesugihanmarak-di-internet-dari-nikahi-jin- pasang-susuk-hingga-banjir-uangtanpa-tumbal? page $=3$

Fatwa Majelis Tarjih, Seputar Upacara tahlilan, hal.1, 27 April 2016, http://m.muhammadiyah.or.id/id/ artikel-seputar-upacara-tahlilandetail-621.html

Keputusan Bahtsul Masail Maudhu'iyah, PWNU Jawa Timur Tentang ISLAM NUSANTARA di Universitas Negeri Malang, 13 Februari 2016, https:// ltnnujabar.or.id/keputusan-bahtsulmasail-maudhuiyah-pwnu-jawatimur-tentang-islam-nusantara/

Nugraha Entra. Sikap Muhammadiyah Tentang Tahlilan. 12 Mei 2013. https://www. kompasiana.com/nugrahaentra/55 282af5f17e6197218b45d5/sikapmuhammadiyah-tentang-tahlilan

\section{HASIL DISKUSI}

\section{Pertanyaan}

1. Amaranggana Ratih Mradipta (Universitas Negeri Yogyakarta)

Tadi pembahasannya mengenai Mistik dan Islam Dalam Masyarakat Jawa menggunakan metode Historigrafi, pertanyaannya heuristiknya bagaimana caranya? Menggunakan sumber sejarah lisan darimana dan dimana titik terhadap bias terhadap masyarakat Jawa menghadapi spiritualitasnya tersebut? Kemudian goalsnya dalam penelitian ini apa? Apakah memaksa Muhammadiyah dan NU untuk mengakui tentang spiritualitas ini atau ada goals lainnya?

\section{Yaser Arafat, M.A (Universitas Islam} Negeri Sunan Kalijaga Yogyakarta)

Pembahasan mistik dari sisi yang mas mau angkat sudah banyak dibahas, lebih baik membahas dari 
sisi bagaimana mistik tersebut mengalami popularisasi atau mungkin terobosan baru seperti santet. Mungkin bisa dikaji perubahan materi menjadi energi, kemudian sampai bentuk materi lagi.

\section{Jawaban}

1. Terkait dengan metodologi, yang jelas titik fokus pada penelitian ini berkaitan sikap ataupun perilaku spiritual sehingga dalam mengumpulkan data-data dengan ada beberapa buku seperti pemuda NU yaitu jimat NU. Disitu ada penjelasan, bagaimana NU menyikapi persoalan mistik. Memang ada dua kelompok yang bersikap akomodatif, tetapi harus tetap berpegang pada prinsip-prinsip syariah. Untuk Muhammadiyah saya melihat keputusan Majelis Tarjih yang menyatakan secara tegas menolak, termasuk pengajian tahlilan 7 hari, 40 hari. Baru bahan ini yang saya perdalam kaji. Jika ingin membandingkan dengan kelompok yang lain, saya mencoba mendengar dari beberapa ceramahnya.
Lalu seluruhnya saya merangkum dan melihat pandangan mereka soal mistik tersebut (itu historiografi nya). Tujuan lainnya dari penelitian ini adalah orang/ individu harusnya memiliki kesadaran spiritualitas. Kesadaran spiritualitas yang positif menurut saya adalah ketika orang tersebut mengalami jalan melalui pengalaman mistik. Kalo tujuan utamanya lebih pada misalnya NU punya sikap ada yang akomodatif dll.

2. Mengenai penelitian ini, saya belum menemukan penelitian lain seperti yang saya buat. Bahwa penelitian mistik seperti ini telah banyak dilakukan, memang itu benar, tapi penelitian sejenis ini yang meneropong sikap NU dan Muhammadiyah, saya yakin belum ada yang melakukan penelitian jenis atau tema ini. Kalau pun ada saya tetap mempertahankan makalah ini dengan tambahan atau pembeda berupa asumsi, sikap,. Jika sudah ada penelitian ini, tapi saya belum menemukan adanya penelitian dengan tema yang sama dengan penelitian saya. 